\title{
Correspondence
}

\section{New method of assessing visual acuity}

SIR, In the article 'New method of assessing visual acuity with pictures' by Hazel Kay' no mention is made of the useful picture test described by Henry F. Allen. ${ }^{2}$ The set of pictures designed by Allen for testing the visual acuity of preschool children meets the objectives for an accurate test set forth by Mrs Kay, namely, one that is 'easily understood by 2-3 year old children, practicable for both examiner and child, and which is graded according to the Snellen's system.'

Dr Allen's picture test has been widely used by ophthalmologists and orthoptists in the United States and probably elsewhere during the past 25 years. It is readily available from ophthalmic equipment companies in the United States. Jules Stein Eye Institute,

LEONARD APT Department of Ophthalmology,

School of Medicine,

University of California, Los Angeles, USA

\section{References}

$1 \mathrm{Kay} \mathrm{H}$. New Method of assessing visual acuity with pictures. Br J Ophthalmol 1983; 67: 131-3.

2 Allen HF. A new picture series for preschool vision testing. Am J Ophthalmol 1957; 44: 38-41.

SIR, At the time of writing my article I was not familiar with the vision test that Dr Apt refers to in his letter. As far as I know the test is not used or even available in this country, and it was not referred to in any of the literature that I had access to during my research. However, I have since obtained a copy of Dr Allen's article and would like to make the following points.

(1) Dr Allen makes no mention of the test being easily understood by children under the age of 3. (2) I believe that Dr Allen's test consists of too few pictures to maintain a small child's attention and interest for the required length of time. I understand that the same 8 pictures are shown repeatedly at increasing distances from the child, which introduces a risk of the child remembering them or becoming bored. (3) Altering the fixation distance instead of the picture size involves changes in the accommodative state of the eye which can affect the resultant acuity. (4) Comparability with Snellen's letters seems unlikely, since although Dr Allen recognises the importance of pictures being constructed in the same way, with constant line width, ('fine lines below the threshold angle disappear entirely. Thick lines appear as black blobs ... .) his pictures are clearly not constructed on this basis. The results of his survey comparing the accuracy of his test with Snellen's acuity are unimpressive. He cites only 4 cases, in all of which the vision of the amblyopic eye is shown to be considerably better when tested with his pictures.

I cannot accept, therefore, Dr Apt's claim that Dr Allen's pictures meet the criteria for an accurate picture visual acuity test as stated in my article and as fulfilled by my own test. However, as I have limited knowledge of current use of
Dr Allen's test, I would welcome correspondence from $\mathrm{Dr}$ Apt or anyone else who has details of more recent research into its use and effectiveness. 32 Zetland Avenue North,

H. KAY Bolton BL3 3QT.

\section{Book reviews}

Documenta Ophthalmologica Proceedings Series 32. Strabismus Symposium, Amsterdam 1981. Eds. A. Th. M. van Balen and W. A. Houtman. Pp. 284. Dfl.140.00. W. Junk: The Hague. 1982.

The president (Professor Kurt Cuppers) reminded his audience that the original title of the Strabismological Symposia held in Europe was the CESSD (Concilium Europaeum Strabismi Studio Deditum), which was founded in Paris in 1961 by $\mathrm{Dr}$ Thomas under the direction of Professor Jules François. Its task consisted in arranging regular meetings to discuss problems of strabismology and co-ordinating them and passing the results on to various national working parties.

From the beginning the CESSD was a European organisation, at first limited to Western Europe. However in 1964, thanks to the efforts of Thomas, whose contacts with the World Health Organisation created the possibility of the CESSD being joined by representatives of the so-called Iron Curtain countries in Eastern Europe, this was duly carried out. The CESSD has never been a strabismological society in the usual meaning but, as Professor Cuppers sees it, an all-European committee (or council) which has the task of creating contacts for material understanding and for endeavouring to achieve harmony. The fact that in addition symposia, with admission of nonmembers, have been organised by the respective national representatives does not in the view of Professor Cuppers change its fundamental structure.

The publication of this symposium includes all the papers that were given. Part 1 started first with those concerned with physiological problems such as fixation disparity, anomalous fusion, sensorial interactions in re-educated strabismic amblyopia, and binocularity in comitant esotropia and exotropia. It also included a report on the results of the Cuppers Faden operation in cases of alternating congenital convergent strabismus, the possibility of correct fusion-formation of adults, and the early onset of esotropia. There was also a new hypothesis on latent nystagmus and on the congenital squint syndrome, and the influence of progressive press-on prisms on changing squinting angles.

Part 2 was concerned with noncomitant squint, starting with basic motor mechanisms in paretic squint, primary overaction of the inferior oblique muscle, the treatment of noncomitant strabismus, Duane's retraction syndrome, and oculomotor imbalance in congenital ptosis.

The meeting finished with an excellent round-table discussion chaired by Dr Crone on the subject of 'Posterior fixation suture in noncomitent squint' with special reference to the Faden operation. The 7 participants were Drs De 